\title{
Erratum to: A Randomized Controlled Single-Blind Study Demonstrating Superiority of Amniotic Suspension Allograft Injection over Hyaluronic Acid and Saline Control for Modification of Knee Osteoarthritis Symptoms
}

Jack Farr, MD ${ }^{1}$ Andreas H. Gomoll, MD ${ }^{2}$ Adam B. Yanke, MD, PhD ${ }^{3} \quad$ Eric J. Strauss, MD 4 Katie C. Mowry, PhD ${ }^{5}$ and ASA Study Group*

${ }^{1}$ Knee Preservation and Cartilage Restoration Center, Ortholndy, Indianapolis, Indiana

2 Department of Orthopaedic Surgery, Hospital for Special Surgery, Address for correspondence Jack Farr, MD, Knee Preservation and Cartilage Restoration Center, Ortholndy, 1260 Innovation Pkwy, New York

${ }^{3}$ Section of Cartilage Restoration and Sports Medicine, Department Greenwood, Indiana 46143 (e-mail: jfarr@orthoindy.com). of Orthopaedic Surgery, Rush University Medical Center, Chicago, Illinois

${ }^{4}$ Department of Orthopaedic Surgery, NYU Langone Medical Center, New York

${ }^{5}$ Department of Research and Development, Organogenesis Inc.,

Birmingham, Alabama

J Knee Surg 2019;32:e2.

ERRATUM

It has been brought to the publisher's attention that the above article was published online under the incorrect open access license category (CC BY-NC ND) in The Journal of Knee Surgery, Volume 32, Number 11 (DOI: 10.1055/s-0039-1696672). The correct license is "CC BY."

For details of the ASA Study Group members, please refer the Acknowledgments section provided in the original article.

DOI https://doi.org/ 10.1055/s-0039-3402742. ISSN 1538-8506.
License terms

(c) (1) 